\title{
New trends in mechanics of masonry
}

\author{
Elio Sacco • Daniela Addessi · Karam Sab
}

Published online: 5 March 2018

(C) Springer Science+Business Media B.V., part of Springer Nature 2018

Masonry constructions are an important part of the historic and architectural heritage of many countries and the analysis of their safety conditions, as well as the design of repair and strengthening interventions, is a challenging task. Many efforts have been devoted in the past to develop methodologies able to accurately reproduce masonry structural response. Relevant and even pioneer contributions can be found proposing analytical methods to evaluate the limit load of masonry elements, such as walls and arches. Simplified approaches have been also formulated to analyze masonry construction behavior under vertical and horizontal loading conditions, developing easy and fast procedures. Owing to the enormous advancement of the computational tools, the last decades have witnessed a wide spread of the numerical modeling techniques, especially in the field of mechanics of heterogeneous materials like masonry. Therefore, a large variety of numerical models for masonry has been formulated and applied to reproduce experimental and real cases.

E. Sacco $(\square)$

University of Naples Federico II, Naples, Italy

e-mail: elio.sacco@unina.it

D. Addessi

Sapienza University of Rome, Rome, Italy

K. Sab

Ecole des Ponts ParisTech, Champs-sur-Marne, France
Meccanica journal has always shown a great interest in the Mechanics of Masonry. This is testified by the significant amount of papers published on this topic. Moreover, Meccanica published a special issue entitled 'Masonry Construction: Structural Mechanics and Other Aspects' and edited by C. R. Calladine in 1992, in honor of Professor Heyman as a tribute to his seminal work in the field of masonry constructions.

After 25 years, we thought that was time to publish a new special issue that takes stock of the advancements in this field.

This Special Issue aims to collect the recent contributions of invited researchers, whose expertise in the field of modeling masonry material and structures is well known. It contains a collection of 20 papers focusing on different aspects of masonry constructions, modeling and analysis. The contributions are grouped into seven main categories, that are: micromechanical models, homogenization and multiscale procedures, macromechanical approaches, simplified macro-element formulations, limit analysis methods, arches and vaults modeling, real cases analysis. This is just a criterion to order the papers. Of course, some of the papers contain topics belonging to more than one group, and these are grouped according to the most characterizing.

Micromechanical approaches are based on the distinct modeling of the masonry constituents, adopting different constitutive laws for bricks/blocks and mortar joints, whose mechanical properties are 
derived via experimental tests on each constituent. These methods, requiring very high computational costs, are suitable to simulate laboratory experimental tests or investigate the response of masonry structures characterized by superimposed big blocks.

In this context, the mechanical behavior of the straight and spiral staircases is investigated in [1] adopting the discrete element method. The study remarks that significant torsion moments occur in the treads, while bending moments are much smaller than in a free cantilever, the connection between wall and treads play a fundamental role in the value of the internal forces and stress distributions, and lastly approximate modeling could strongly underestimate the torsional moment for spiral stairs.

A micromechanical analysis for masonry made of bricks and mortar joints is presented in [2]; the bricks are modeled using 3D elastic solid elements and zero thickness interfaces characterized by nonlinear response are adopted to model the mortar joint and the mortar-brick interaction. A damage-plasticity constitutive model is proposed for the interfaces, based on the introduction of an anisotropic damage tensor, whose evolution is coupled to the produced plastic work. Tensile and compressive normal damages are introduced to account for the unilateral effect due to the crack re-closure. The response of the typical interface point is illustrated and the analysis of a shear wall is performed comparing the numerical results with the experimental evidences.

A comparison between different modeling techniques to study the response of in-plane loaded masonry walls is proposed in [3]. In particular, the discrete element method (DEM), the discrete/finite element method (DEM/FEM) and a continuum model based on the homogenization analysis are discussed for regular masonry. Bricks are modeled as rigid for DEM and homogenization model, while elastic deformations are considered in the DEM/FEM computations. The nonlinear response of the masonry is accounted for considering elastic-plastic joints based on the Mohr-Coulomb yield criterion. Numerical applications are developed with the aim of investigating the effectiveness of the considered numerical models and evaluating the sensitivity of masonry response to panel dimension ratio and material texture.

A numerical model based on the discrete element method is proposed in [4] and validated towards experimental results on half-scale tilting tests on dry- stacked stone masonry structures carried out at the University of Pavia and four-point bending tests made on masonry wallettes at the McMaster University. Then, the numerical model is used to investigate the effects of the dilatancy of the interfaces and the size of the building blocks on the strength of masonry structures.

The micromechanical approach adopted in [5] separately models blocks, mortar joints and a third thin layer interposed between them. Large displacements and damage constitutive response are assumed for this new third component, adopting the Saint Venant-Kirchhoff formulation and the Kachanov theory and using asymptotic techniques to derive the governing equations. The numerical results are compared with experimental outcomes on shear masonry walls.

The multiscale modeling is the most recent and very promising approach for the analysis of masonry structural elements. Two scales are commonly defined, the macroscale at the structural level and the microscale, where a material representative volume element (RVE) is studied. Relying on the separation of scale assumption, homogenization techniques can be suitably adopted to derive the unknown constitutive relationship of the equivalent homogeneous medium at the macroscale. At the microscale, all the constituents are modeled in detail taking into account their geometrical arrangement, size and specific nonlinear constitutive laws. To connect the two scales proper bridging conditions are formulated.

In this framework, a homogenization technique is presented in [6] to derive the strength domain of stone masonry, and the kinematic theorem of the limit analysis is used at the macroscale in a 2D framework. The developed computational technique is used to simulate a reduced-scale experimentation, developed for three different geometries of drystone masonry walls loaded by backfill. Comparison between numerical and laboratory results are illustrated in terms of failing load and failure mechanism, experimentally recovered performing the particle image velocimetry technique. A multiscale computational strategy for the analysis of in-plane loaded masonry walls characterized by regular texture is presented in [7]. At the microscale, bricks are considered as linear elastic, while mortar joints are modeled by interfaces characterized by nonlinear response. Two different numerical techniques are adopted to solve the boundary 
value problem at the macro and microscale, that is the finite element is used at the macroscale and a meshless technique is implemented to solve the homogenization problem. Macroscopic localization of plastic bands is obtained performing a spectral analysis of the tangent stiffness matrix and numerical examples on running bond masonry specimens are developed. The out-ofplane response of masonry 1D structural elements, like columns and strips of long walls, is studied in [8]. To this end, the Timoshenko beam model is adopted at both the macroscopic and microscopic scale, considering the periodic medium made by the translation along one direction of a unit cell. This last is selected as the superposition of a linear elastic brick and a damage-plastic mortar bed joint. A semi-analytical homogenization procedure is proposed and numerical applications are performed, comparing the results with the available experimental outcomes.

An interesting issue is the analysis of not periodic masonry characterized by irregular texture, so that the homogenization cannot be performed on a unit cell. This problem is dealt with in [9] to derive the failure surface of quasi-periodic masonry via the analysis of the statistically equivalent periodic unit cell and the mean stresses approach. The critical states are detected by means of an overall failure criterion based on the strength of the constituents of the heterogeneous medium. Multiscale analysis of irregular masonry is also presented in [10], developing an efficient strategy for the generation and automated finite element discretization of RVE, based on distance fields and level set functions. The mortar material damaging behavior is simulated by adopting a gradient damage model and the compressive-shear failure envelope of the RVE is derived. Moreover, the effect of a decreasing gradient effect is also investigated.

Macromechanical models are based on the use of phenomenological constitutive laws for the masonry material, considered as a fictitious homogenized medium. These are derived by performing tests on small assemblage of bricks/blocks and mortar and usually rely on constitutive modeling with inner variables, such as friction-plasticity and damage. Typically, this modeling approach is very effective from a computational point of view. In this framework, a numerical procedure based on a tracking algorithm able to describe the localized cracking in masonry structures subjected to in-plane cyclic actions, together with an improvement of a tension- compression damage model for the description of irreversible shear strains, is presented in [11]. The enhanced model is validated against an experimentally tested shear masonry wall under quasi-static shear loading. A full 3D hyperelastic constitutive model with bounded tensile and compressive strength for masonry is proposed in [12], where the maximum value of the tangential stress on each plane depends on the normal component. The corresponding developed finite element formulation is used to study masonry panels under in-plane and out-of-plane loading.

No-tension models can also successfully simulate the response of masonry constructions, basing on the very low tensile strength of masonry with respect to the compressive one. In this context, a variational approach of the free discontinuity method is proposed in [13] to determine the collapse load and mechanism. The proposed formulation is validated via numerical applications concerning the analysis of masonry walls and arches subjected to different loading conditions.

A simplified but very efficient approach for the analysis of large (regular) buildings is based on the adoption of the so-called macroelements for the discretization of each wall as an assemblage of piers, spandrels and rigid nodes. The macroelement is usually made of the assemblage of rigid/linear/ nonlinear elements connected by special joints characterized by nonlinear response.

The macroelement approach is adopted for evaluating the collapse load of a masonry construction in [14], where the structure is regarded as the assemblage of simple repetitive units, consisting of two piers connected by a spandrel. Piers and spandrel are assumed as rigid bodies, joined each other by means of nonlinear interfaces with zero tensile strength and a limited compressive strength. The collapse load is evaluated solving the equilibrium nonlinear equations. Numerical applications are illustrated, comparing the results obtained using the proposed technique with experimental evidences. Analogously, a structural model consisting of rigid bodies joined by nonlinear interfaces is presented in [15], where the mechanical response for the interface is recovered via a homogenization procedure. To this end, a running bond masonry is considered characterized by nonlinear response of the mortar joints. The model is applied to study the behavior of a church façade interconnected with a portion of the perpendicular walls and of a small masonry building. Comparison with experimental 
results are reported proving the effectiveness of the proposed modeling approach. The prediction of the crack pattern produced by settlements in masonry constructions is investigated in [16] by using the extension of the Heyman model. The kinematical admissible solution is searched by minimizing the potential energy of the structure within a set of piecewise rigid displacements and by performing a finite element subdivision into rigid blocks. Two real case studies are finally analyzed.

The limit analysis is a very effective tool to estimate the upper and lower bounds of the collapse load for masonry structures. In this field, an upper bound limit analysis approach is proposed in [17] to investigate the collapse of out-of-plane loaded masonry walls. The innovative technique of the Non-Uniform Rational B-Spline (NURBS) is adopted to describe typical geometries of masonry walls presenting openings with arbitrary shape. A homogenization technique is used to derive the failure surface of the masonry, which accounts for the low tensile strength and anisotropic behavior of the masonry. Numerical applications show the performances of the proposed modeling approach.

Arches and vaults are typical structural elements for masonry constructions. The in-plane static response of masonry arches is studied in [18] by modeling the arch as a curved beam and by solving the free-boundary nonlinear differential problem via an ad hoc iterative procedure. This permits to describe the arch equilibrium path up to collapse. A phenomenological piecewise-linear constitutive law is adopted, with bounded tensile and compressive strengths. The model is validated on the basis of some numerical and experimental results available in literature.

The scale-model testing is proposed in [19] as a tool to study the three-dimensional collapse behavior of vaulted masonry structures and discrete-element assemblies. Different experiments are performed on a 3D-printed model of a cross vault, using forcesensitive robotic arms to apply loads in different locations and differential settlement of the supports together with an optical measuring system. The proposed approach is proved to be a flexible and comprehensive solution for the assessment of the masonry structural behavior.

Finally, the complex structure of the Cathedral of Ica, Peru, is studied in [20] performing finite element analyses to design proper seismic retrofitting interventions. The nonlinear behavior of masonry is simulated by considering specified compressive and tensile softening response, while isotropic homogeneous and linear behavior is adopted for modeling timber with proper assumptions on the connections. Nonlinear static and dynamic analyses allow to evaluate the dominant mode shapes of the structure, validate the numerical models by reproducing the structural damage observed in situ, estimate the structural performance and identify the main failure mechanisms.

\section{References}

1. Rigò B, Bagi K (2017) Discrete element analysis of stone cantilever stairs. Meccanica. https://doi.org/10.1007/ s11012-017-0739-5

2. Minga E, Macorini L, Izzudin BA (2017) A 3D mesoscale damage-plasticity approach for masonry structures under cyclic loading. Meccanica. https://doi.org/10.1007/s11012017-0793-z

3. Baraldi D, Reccia E, Cecchi A (2017) In plane loaded masonry walls: DEM and FEM/DEM models. A critical review. Meccanica. https://doi.org/10.1007/s11012-0170704-3

4. Godio M, Stefanou I, Sab K (2017) Effects of the dilatancy of joints and of the size of the building blocks on the mechanical behaviour of masonry structures. Meccanica. https://doi.org/10.1007/s11012-017-0688-z

5. Raffa ML, Lebon F, Rizzoni R (2017) Derivation of a model of imperfect interface with finite strains and damage by asymptotic techniques. Application to masonry structures. Meccanica. https://doi.org/10.1007/s11012-017-0765-3

6. Terrade B, Colas A-S, Garnier D (2017) Upper bound limit analysis of masonry retaining walls using PIV velocity fields. Meccanica. https://doi.org/10.1007/s11012-0170673-6

7. Giambanco G, La Malfa Ribolla E, Spada A (2017) Meshless meso-modeling of masonry in the computational homogenization framework. Meccanica. https://doi.org/10. 1007/s11012-017-0664-7

8. Addessi D, Sacco E (2017) Homogenization of heterogeneous masonry beams. Meccanica. https://doi.org/10.1007/ s11012-017-0758-2

9. Calavagli N, Cluni F, Gusella V (2017) Failure surface of quasi-periodic masonry by means of Statistically Equivalent Periodic Unit Cell approach. Meccanica. https://doi.org/10. 1007/s11012-017-0771-5

10. Massart TJ, Sonon B, Kamel KEM, Hien Poh L, Sun G (2017) Level set-based generation of representative volume elements for the damage analysis of irregular masonry. Meccanica. https://doi.org/10.1007/s11012-017-0695-0

11. Saloustros S, Cervera M, Pela L (2017) Tracking multidirectional intersecting cracks in numerical modeling of masonry shear walls under cyclic loading. Meccanica. https://doi.org/10.1007/s11012-017-0712-3 
12. Lucchesi M, Pintucchi B, Zani N (2017) Bounded shear stress in masonry-like bodies. Meccanica. https://doi.org/ 10.1007/s11012-017-0719-9

13. Fortunato A, Fabbrocino F, Angelillo M, Fraternali F (2017) Limit analysis of masonry structures with free discontinuities. Meccanica. https://doi.org/10.1007/s11012-017-06638

14. Caporale A, Raimondo L (2017) Predictive model for the collapse load of masonry assemblage with two piers joined by a spandrel. Meccanica. https://doi.org/10.1007/s11012017-0694-1

15. Bertolesi E, Milani G, Casolo S (2017) Homogenization towards a mechanistic Rigid Body and Spring Model (HRBSM) for the non-linear dynamic analysis of 3D masonry structures. Meccanica. https://doi.org/10.1007/ s11012-017-0665-6

16. Iannuzzo A, Angelillo M, De Chiara E, De Guglielmo F, De Serio F, Ribera F, Gesualdo A (2017) Modeling the cracks produced by settlements in masonry structures. Meccanica. https://doi.org/10.1007/s11012-017-0721-2

17. Chiozzi A, Milani G, Grillanda N, Tralli A (2017) A fast and general upper-bound limit analysis approach for outof-plane loaded masonry walls. Meccanica. https://doi.org/10.1007/ s11012-017-0637-x

18. Barsotti R, Bennati S (2017) A simple and effective nonlinear elastic one-dimensional model for the structural analysis of masonry arches. Meccanica. https://doi.org/10. 1007/s11012-017-0711-4

19. Barentin CC, Van Mele T, Block P (2017) Robotically controlled scale-model testing of masonry vault collapse. Meccanica. https://doi.org/10.1007/s11012-017-0762-6

20. Ciocci MP, Sharma S, Lourenço PB (2017) Engineering simulations of a super-complex cultural heritage building: Ica Cathedral in Peru. Meccanica. https://doi.org/10.1007/ s11012-017-0720-3 